\title{
Study of Ink Jet Print Resistance Using Various Colour Difference Formulas
}

\author{
Barbara BLAZNIK, Sabina BRAČKO
}

\begin{abstract}
Three frequently used formulas and their power function modifications were used to calculate the colour differences after the exposure to light and to study the stability of ink jet prints by spectrophotometric measurements. The prints were exposed to the simulated daylight of different spectral composition at constant conditions of temperature and relative humidity. According to the results, the black prints were the least affected and the magenta prints exhibited the biggest colour differences. The most resistant have proven to be the prints on archival paper which contained no optical brightening agents. The presence of shortwave radiation between 320 and $300 \mathrm{~nm}$ additionally diminished the resistance of prints. The same conclusions were obtained regardless of the colour difference formula applied, with one exception. Generally, the CIEDE2000 formula performed the best, especially when comparing samples with a smaller colour difference.
\end{abstract}

Keywords: CIE94; CIEDE2000, CIELAB; colour difference; colour measurement; ink jet; print resistance

\section{INTRODUCTION}

Characteristics of the materials and their longevity have been in the focus of investigations for several years [1-3]. This also applies to the prints on paper which represent valuable documents intended for long time usage and archiving $[4,5]$. The changes which occur on the material during the time can be noticed when comparing a coloured product to a defined standard or they can emerge on a product itself as a result of different external factors, such as light, heat, and humidity $[6,7]$. Those changes can be successfully examined also by the colorimetry $[8,9]$. An accurate description of colour difference is in several circumstances even more important than an exact definition of colour itself.

Colour difference evaluation represents one of the classical fields in colour science [10]. The colour differences can be described on the basis of mathematical equations which are defined in a suitable colour space. In this procedure, it is essential that the calculated value represents the visual colour difference. During the last decades, three colour difference formulas were widely used in different areas of research and industry $[11,12]$. In 1976, CIE recommended the CIELAB colour space and the formula according to which the colour difference was defined as a distance between the two samples in the colour space (Eq. (1)) [13]:

$$
\Delta E_{a b}^{*}=\sqrt{\left(\Delta L^{*}\right)^{2}+\left(\Delta a^{*}\right)^{2}+\left(\Delta b^{*}\right)^{2}}
$$

The CIELAB formula was set for evaluation of flat reflective samples on neutral grey to white background [14]. It exhibits certain deficiencies and, consequently, the calculated values are not in accordance with the perceived colour differences in some cases. The discrepancies can be obvious especially in the region of darker samples. It was also established that the inconsistency of testing conditions could lead to poorer results. The CIE94 formula (Eq. 2) was therefore defined with regard to the basic conditions, which were set in accordance with those usually set in industrial colour difference assessments [15]: the samples should be observed under illumination simulating standard illuminant D65, with illumination 1000 lux, against a uniform grey background with $L^{*}=50$, the specimens are homogenous in colour and they are placed in direct edge contact, the sample size is greater than 4 degrees subtended visual angle, the observer is a person with normal colour vision. The parametric factors $k_{\mathrm{L}}, k_{\mathrm{C}}, k_{\mathrm{H}}$ were used to describe the deviation from reference conditions [15]

$$
\Delta E_{94}^{*}=\sqrt{\left(\frac{\Delta L^{*}}{k_{\mathrm{L}} S_{\mathrm{L}}}\right)^{2}+\left(\frac{\Delta C_{a b}^{*}}{k_{\mathrm{C}} S_{\mathrm{C}}}\right)^{2}+\left(\frac{\Delta H_{a b}^{*}}{k_{\mathrm{H}} S_{\mathrm{H}}}\right)^{2}}
$$

Despite the improvements, CIE94 formula exhibits some limitations, especially in the blue region and with neutral colours. To overcome these limitations, the CIEDE2000 was developed and set as a standard [16]. This formula corrects the non-uniformity of the CIELAB colour space for small colour differences under reference conditions [17]. Due to the complex calculation procedure, greater precision is assured especially in the case of smaller colour differences.

$$
\Delta E_{00}^{*}=\sqrt{\left(\frac{\Delta L^{\prime}}{k_{\mathrm{L}} S_{\mathrm{L}}}\right)^{2}+\left(\frac{\Delta C^{\prime}}{k_{\mathrm{C}} S_{\mathrm{C}}}\right)^{2}+\left(\frac{\Delta H^{\prime}}{k_{\mathrm{H}} S_{\mathrm{H}}}\right)^{2}+R\left(\frac{\Delta C^{\prime}}{k_{\mathrm{C}} S_{\mathrm{C}}}\right) \cdot\left(\frac{\Delta H^{\prime}}{k_{\mathrm{H}} S_{\mathrm{H}}}\right)}(3)
$$

Recently, it was established that a simple modification of original colour difference formula substantially improves the correspondence between the calculated and perceived colour difference. The application of power function (Eq. (4)) can contribute to better performance, where $\Delta \mathrm{E}$ represents the colour difference calculated with one of the original colour difference formulas (Eq. (1)-(3)). $a$ and $b$ are the coefficients calculated on the basis of extensive studies [10].

$\Delta E^{\prime}=a \Delta E^{b}$

Colour difference formulas represent a valuable tool for studying the processes which occur on material with time during its use and storage. However, the results are only reliable if the calculated values are in accordance with the realistic changes. The selection of a suitable colour difference formula is therefore of crucial importance [11, $12,18]$.

The purpose of the present investigation was to examine the stability of the ink jet prints on the basis of 
various colour difference formulas. Three widely used formulas were applied together with their power function modifications. The correspondence between the calculated and observed colour differences was analysed on the basis of Pearson's correlation coefficient, $R^{2}$. Besides the STRESS method, this procedure has been commonly used to examine the performance of colour difference formulas $[19,20]$.

The aim of the present research was to find out which formula enables the best agreement with visual perception and to establish whether different colour difference formulas can lead to different conclusions regarding the properties of the samples, in our case, the stability of the prints.

\section{EXPERIMENTAL}

\subsection{Printed Samples} prints.

Three different paper grades were used for colour

- P1: archival paper; non-acidic, includes 30\%

PCW fibres,

- P2: office paper; intended for a broad range of use,

- P3: permanent paper; produced in accordance with permanence and durability requirements.

Tab. 1 shows the basic properties of paper samples $\mathrm{P} 1-$ P3 which were measured in accordance with standards ISO
536, ISO 534 and ISO 2144. An ink jet printer Office 6000 (Hewlett Packard, USA) with the maximum print resolution $4800 \times 1200 \mathrm{dpi}$ was used. The PrintFab, the printer driver, was used to produce the prints of size $4,4 \times$ $2,4 \mathrm{~cm}$ with $100 \%$ intensity in cyan $(\mathrm{C})$, magenta $(\mathrm{M})$, yellow (Y) and black (K).

Table 1 Grammage, thickness, specific volume and ash content of papers $\mathrm{P} 1$, $\mathrm{P} 2$ and $\mathrm{P} 3$

\begin{tabular}{|l|c|c|c|}
\hline \multirow{2}{*}{ Paper properties } & \multicolumn{3}{c|}{ Paper samples } \\
\cline { 2 - 4 } & P1 & P2 & P3 \\
\hline Grammage $($ manufacturer $)\left(\mathrm{g} / \mathrm{m}^{2}\right)$ & 90 & 80 & 80 \\
\hline Grammage $\left(\mathrm{g} / \mathrm{m}^{2}\right)$ & 88.5 & 79.1 & 81.8 \\
\hline Thickness $(\mu \mathrm{m})$ & 126 & 101 & 102 \\
\hline Specific volume $\left(\mathrm{cm}^{3} / \mathrm{g}\right)$ & 1.42 & 1.28 & 1.24 \\
\hline Ash content at $525^{\circ} \mathrm{C}(\%)$ & 11.4 & 23.2 & 11.7 \\
\hline
\end{tabular}

\subsection{Exposure to Light}

The exposure of printed samples to light was made using Xenotest Alpha (Atlas, USA) with two different filter systems which enable the simulation of average daylight in open space or behind the window glass (Xenochrome 300, $\lambda>300 \mathrm{~nm}$, or Xenochrome $320, \lambda>320 \mathrm{~nm}$, respectively). The prints were exposed for 96 hours under conditions of constant temperature and relative humidity $\left(T=35^{\circ} \mathrm{C}, \mathrm{RH}\right.$ $=35 \%$ ). A half of each sample was covered to enable the comparison between the exposed and non-exposed part of the sample and to investigate the influence of the spectral composition of radiation on the stability of the prints.

Table 2 Visual $\left(\Delta E_{\mathrm{F}}\right)$ and calculated $\left(\Delta E_{a b}^{*}, \Delta E_{94}^{*}, \Delta E_{00}^{*}, \Delta E_{a b}^{\prime}, \Delta E_{94}^{\prime}\right.$ and $\left.\Delta E_{00}^{\prime}\right)$ colour differences after exposure to light

\begin{tabular}{|c|c|c|c|c|c|c|c|c|c|}
\hline Wavelength (nm) & Paper sample & Colour & $\Delta E_{\mathrm{F}}$ & $\Delta E^{*}{ }_{a b}$ & $\Delta E_{94}^{*}$ & $\Delta E^{*}{ }_{00}$ & $\Delta E_{a b}^{\prime}$ & $\Delta E_{94}^{\prime}$ & $\Delta E_{00}^{\prime}$ \\
\hline \multirow{12}{*}{$>300$} & \multirow{4}{*}{ P1 } & $\mathrm{C}$ & 1.19 & 4.93 & 2.76 & 2.44 & 3.03 & 2.87 & 2.67 \\
\hline & & $\mathrm{M}$ & 8.67 & 21.23 & 14.39 & 12.66 & 6.76 & 9.12 & 8.45 \\
\hline & & $\mathrm{Y}$ & 0.94 & 13.21 & 3.09 & 3.33 & 5.21 & 3.11 & 3.32 \\
\hline & & $\mathrm{K}$ & 0 & 0.86 & 0.86 & 0.63 & 1.16 & 1.27 & 1.03 \\
\hline & \multirow{4}{*}{$\mathrm{P} 2$} & $\mathrm{C}$ & 1.79 & 11.85 & 6.09 & 5.26 & 4.91 & 4.99 & 4.57 \\
\hline & & $\mathrm{M}$ & 8.67 & 23.93 & 15.37 & 13.99 & 7.22 & 9.55 & 9.07 \\
\hline & & $\mathrm{Y}$ & 1.62 & 14.06 & 3.46 & 3.77 & 5.39 & 3.36 & 3.62 \\
\hline & & $\mathrm{K}$ & 0 & 1.4 & 1.38 & 1.06 & 1.52 & 1.77 & 1.49 \\
\hline & \multirow{4}{*}{ P3 } & $\mathrm{C}$ & 1.49 & 9.16 & 5.12 & 4.36 & 4.26 & 4.42 & 4.01 \\
\hline & & $M$ & 7.81 & 20.44 & 13.64 & 11.95 & 6.62 & 8.78 & 8.12 \\
\hline & & $\mathrm{Y}$ & 0.59 & 11.69 & 2.62 & 2.75 & 4.87 & 2.77 & 2.90 \\
\hline & & $\mathrm{K}$ & 0.08 & 0.63 & 0.63 & 0.49 & 0.98 & 1.02 & 0.87 \\
\hline \multirow{12}{*}{$>320$} & \multirow{4}{*}{ P1 } & $\mathrm{C}$ & 1.36 & 3.96 & 2.16 & 1.93 & 2.69 & 2.42 & 2.27 \\
\hline & & M & 7.29 & 14.3 & 9.91 & 8.81 & 5.44 & 7.02 & 6.56 \\
\hline & & $\mathrm{Y}$ & 1.19 & 12.08 & 2.82 & 3.02 & 4.96 & 2.91 & 3.10 \\
\hline & & $\mathrm{K}$ & 0.08 & 1.22 & 1.21 & 0.88 & 1.41 & 1.61 & 1.31 \\
\hline & \multirow{4}{*}{ P2 } & $\mathrm{C}$ & 1.62 & 10.18 & 5.16 & 4.41 & 4.51 & 4.45 & 4.04 \\
\hline & & M & 7.04 & 15.42 & 10.11 & 9.28 & 5.67 & 7.12 & 6.80 \\
\hline & & $\mathrm{Y}$ & 1.28 & 13.4 & 3.26 & 3.51 & 5.25 & 3.22 & 3.44 \\
\hline & & $\mathrm{K}$ & 1.02 & 1.09 & 1.08 & 0.82 & 1.32 & 1.49 & 1.24 \\
\hline & \multirow{4}{*}{ P3 } & $\mathrm{C}$ & 0.94 & 7.5 & 4.23 & 3.57 & 3.82 & 3.87 & 3.49 \\
\hline & & $\mathrm{M}$ & 8.09 & 13.89 & 9.4 & 8.33 & 5.36 & 6.77 & 6.31 \\
\hline & & $\mathrm{Y}$ & 1.02 & 10.98 & 2.45 & 2.6 & 4.71 & 2.64 & 2.79 \\
\hline & & $\mathrm{K}$ & 0 & 1.18 & 1.18 & 0.88 & 1.38 & 1.58 & 1.31 \\
\hline & & & & & \multicolumn{2}{|c|}{ Power function $a$} & 1.26 & 1.41 & 1.43 \\
\hline & & & & & \multicolumn{2}{|c|}{ Power function $b$} & 0.55 & 0.7 & 0.7 \\
\hline
\end{tabular}

\subsection{Calculation of Colour Difference after Exposure}

The measurements of spectral reflectance on exposed and non-exposed samples were performed by spectrophotometer iOne (X-Rite, USA) in accordance with ISO 13655 standard, using 45/0 standard geometry and white backing with three successive repetitions. The calculations of CIE XYZ and CIE $L^{*} a^{*} b^{*}$ values were made with respect to $10^{\circ}$ standard observer and D65 standard illuminant.

The colour differences $\Delta E^{*}{ }_{a b}, \Delta E^{*}{ }_{94}$ and $\Delta E^{*}{ }_{00}$ between exposed and non-exposed parts of the prints were calculated according to Eqs. (1)-(3) with parametric factors $k_{\mathrm{L}}=k_{\mathrm{C}}=k_{\mathrm{H}}=1$. The colour differences were also calculated using corresponding power functions of original formulas, $\Delta E_{a b}^{\prime}, \Delta E_{94}^{\prime}$ and $\Delta E_{00}^{\prime}$ (Eq. (4)). 


\subsection{Visual Assessment of Colour Difference}

The visual assessment of colour differences after exposure to light was made by ten observers aged 25 to 45 years, five male and five female, which were all tested for normal colour vision [21] using Farnsworth-Munsell 100 HueColour Vision Test. The samples were observed under simulation of average daylight (D65) in the Judge II (XRite) light booth. A grey scale was used to describe the perceived colour change. According to ISO 105-A05 standard, the grey scale rating was transformed into numerical value $\Delta E_{\mathrm{F}}$.

\section{RESULTS AND DISCUSSION}

Tab. 2 shows the colour differences after exposure to light, calculated using the original formulas (Eq. (1)-(3)) and their modifications using power functions (Eq. (4)).

The Pearson's correlation coefficient was used to compare the visual and calculated colour differences and to examine the performance of colour difference formulas [22]. The results are given in Tab. 3.

Table 3 Pearson's correlation coefficient, $R^{2}$, calculated to compare the visual $\left(\Delta E_{\mathrm{F}}\right)$ and calculated $\left(\Delta E^{*}{ }_{a b}, \Delta E^{*}{ }_{94}, \Delta E^{*}{ }_{00}, \Delta E_{a b}^{\prime}, \Delta E_{94}^{\prime}\right.$ and $\left.\Delta E^{\prime}{ }_{00}\right)$ colour differences

\begin{tabular}{|c|c|c|}
\hline \multirow{2}{*}{$\begin{array}{c}\text { Calculated } \\
\text { colour } \\
\text { difference }\end{array}$} & \multicolumn{2}{|c|}{$R^{2}$} \\
\cline { 2 - 3 } & \multicolumn{2}{|c|}{ Visual colour difference range } \\
\hline$\Delta E^{*}{ }_{a b}$ & 0.6283 & $\Delta E_{\mathrm{F}}<2$ \\
\hline$\Delta E^{*}{ }_{94}$ & 0.9177 & 0.5104 \\
\hline$\Delta E^{*}{ }_{00}$ & 0.9155 & 0.6590 \\
\hline$\Delta E^{\prime}{ }_{a b}$ & 0.5311 & 0.7161 \\
\hline$\Delta E^{\prime}{ }_{94}$ & 0.9012 & 0.5645 \\
\hline$\Delta E^{\prime}{ }_{00}$ & 0.8897 & 0.6861 \\
\hline
\end{tabular}

\subsection{Performance of Colour Difference Formulas}

According to the results presented in Tab. 2, the samples show moderate to large changes after the exposure to light. Only five of them exhibited CIELAB colour difference, $\Delta E^{*}{ }_{a b}$, bellow two units. We decided to examine the performance of different formulas separately for two regions, namely $\Delta E_{\mathrm{F}}<10$ and $\Delta E_{\mathrm{F}}<2$. Those values correspond to approximate CIELAB difference $\Delta E_{a b}^{*}<25$ or $\Delta E_{a b}^{*}<14$, respectively.

In the first case, when observing the whole range of samples, the CIELAB formula performs as the least accurate (Tab. 3 ). On the other hand, very good correlation with visual evaluation was obtained using both CIE94 $\left(R^{2}\right.$ $=0.9177)$ and CIEDE2000 $\left(R^{2}=0.9155\right)$. In the second case, when analysing smaller colour differences, the CIEDE2000 performs the best, although the correlation coefficient is slightly lower $\left(R^{2}=0.7161\right)$. Such results were expected as the CIEDE2000 formula was developed with a focus to describe objectively even smaller differences.

The use of modified equations and application of power functions to the original formulas leads to slightly lower values of correlation coefficients when observing the whole colour difference range. Again, the comparison of CIE94 and CIEDE2000 equations based on Pearson's correlation coefficient reveals a good correlation between visual and calculated values $\left(R^{2}=0.9012\right.$ and $\left.R^{2}=0.8897\right)$.
The analysis of samples which exhibit smaller colour differences shows that application of power functions slightly increases the correlation between the calculated and observed colour difference. In this case, the CIEDE2000 formula together with its modification using the power function performed as the best $\left(R^{2}=0.7253\right)$.

According to the results, the use of CIEDE2000 is recommended for smaller colour differences, even in the observed colour difference range which in our study represents colour difference range $\Delta E^{*}{ }_{a b}<14$. Regarding the results, the application of power function additionally improves the agreement between the calculated and perceived colour differences.

\subsection{Influence of Various Colour Difference Formulas on Ranking of the Samples}

Application of different colour difference formulas results in numerically different values and, consequently, it is possible that the ranking of the samples on the basis of the calculated differences after the exposure to light changes, especially if the differences between the calculated values are small. According to the results, the ranking on the basis of the CIELAB formula differs from the ranking on the basis of the observed changes, i.e. value $\Delta E_{\mathrm{F}}$, with a deviation of 3.42 ranks on the average.

The CIE94 and CIEDE2000 formulas lead to a better correlation with an observed difference, $\Delta E_{\mathrm{F}}$, as the average deviations are 2.29 or 2.25 ranks, respectively. The ranking remains unchanged in case of modified colour difference formulas using the power functions i.e. if the samples are compared on the basis of values $\Delta E_{a b}^{\prime}, \Delta E_{94}^{\prime}$ or $\Delta E^{\prime}{ }_{00}$.

\subsection{Analysis of the Print Resistance Using Various Colour Difference Formulas}

The comparison of the results calculated for the prints of different colour with CIELAB formula shows that the black prints exhibit on average the best resistance to light $\left(\Delta E^{*}{ }_{a b}=1.06\right)$ whereas the magenta prints are the least resistant (average colour difference $\Delta E^{*}{ }_{a b}=18.20$ ) (Fig. 1a). This is very likely to be the consequence of the fact that black inks are usually based on pigments, which are more resistant to light and other external influences than dyes. Although the values calculated using the CIE94 and CIEDE2000 formulas are numerically not the same, they lead to the same conclusions.

However, some deviations appear at comparison of yellow and cyan samples. The average CIELAB colour difference was calculated to be $\Delta E^{*}{ }_{a b}=12.57$ for the yellow prints and $\Delta E^{*}{ }_{a b}=7.93$ for the cyan prints, therefore, we can assume that cyan prints exhibit better light fastness. The calculations on the basis of other two formulas, CIE94 and CIEDE2000, lead to the opposite conclusions as the values $\Delta E^{*}{ }_{94}$ and $\Delta E^{*}{ }_{00}$ for cyan prints are larger than for the yellow ones. This is also evident when applying the modified colour difference formulas with power functions (Fig. 1b). These results show that the selection of the colour difference formulas can influence the evaluation of the print resistance and the comparison of the samples.

The composition of the ink is not the only factor which influences the resistance of the prints, it also depends on 
the substrate, i.e. paper used. Previous results [9] show that the presence of optical brightening agents strongly affects the light fastness of both paper and print. The results of our investigations confirm such findings as the smallest colour differences were observed and calculated for the prints on paper P1, the archival paper, which is intended for long time use and storage and was produced without optical brightening agents. Regardless of the type of colour difference formula used, all of the calculated values confirm such results (Fig. 2).

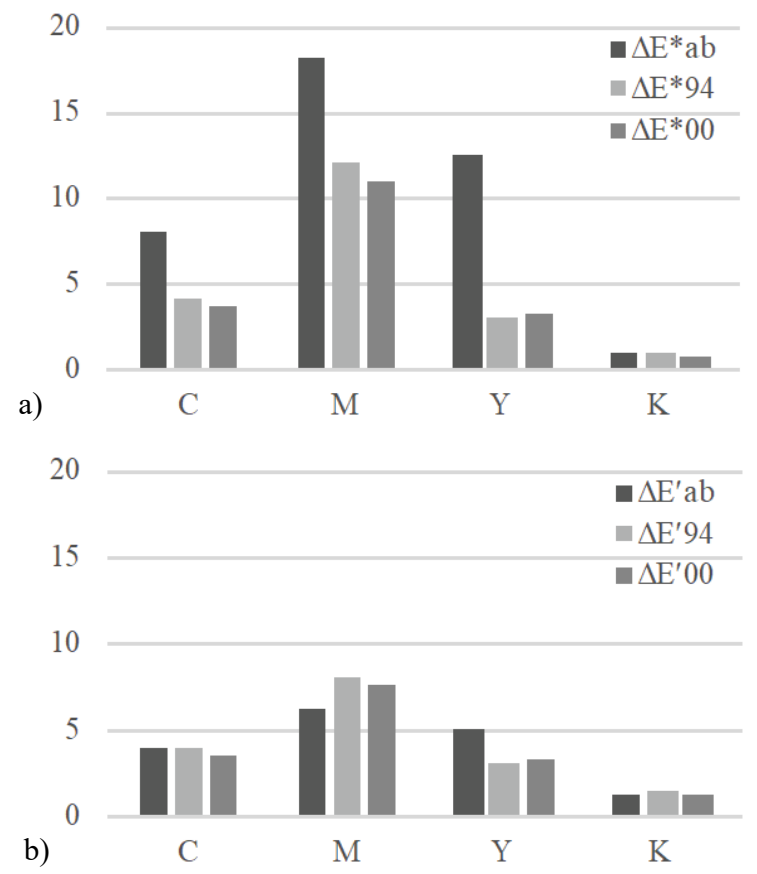

Figure 1 Average colour differences for cyan $(C)$, magenta $(M)$, yellow $(Y)$ and black (K) colour samples; a) calculated according to the CIELAB, CIE94 and CIEDE2000 formulas; b) modified colour difference formulas CIELAB, CIE94 in CIEDE2000 using power functions
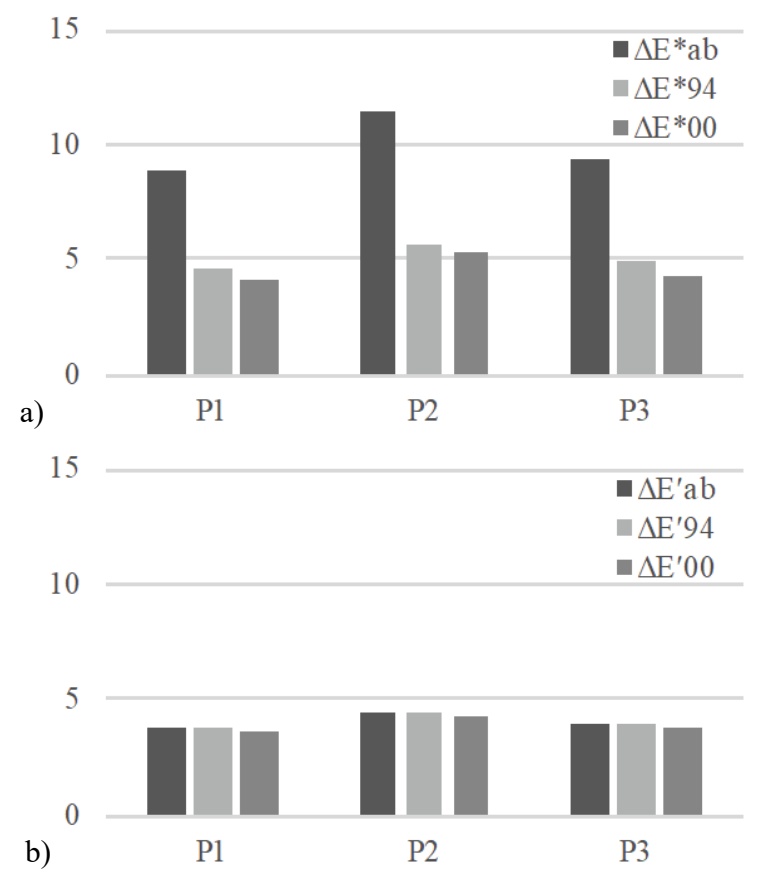

Figure 2Average colour differences for prints on paper samples P1, P2 and P3. a) calculated according to the CIELAB, CIE94 and CIEDE2000 formulas; b) modified colour difference formulas CIELAB, CIE94 and CIEDE2000 using power functions

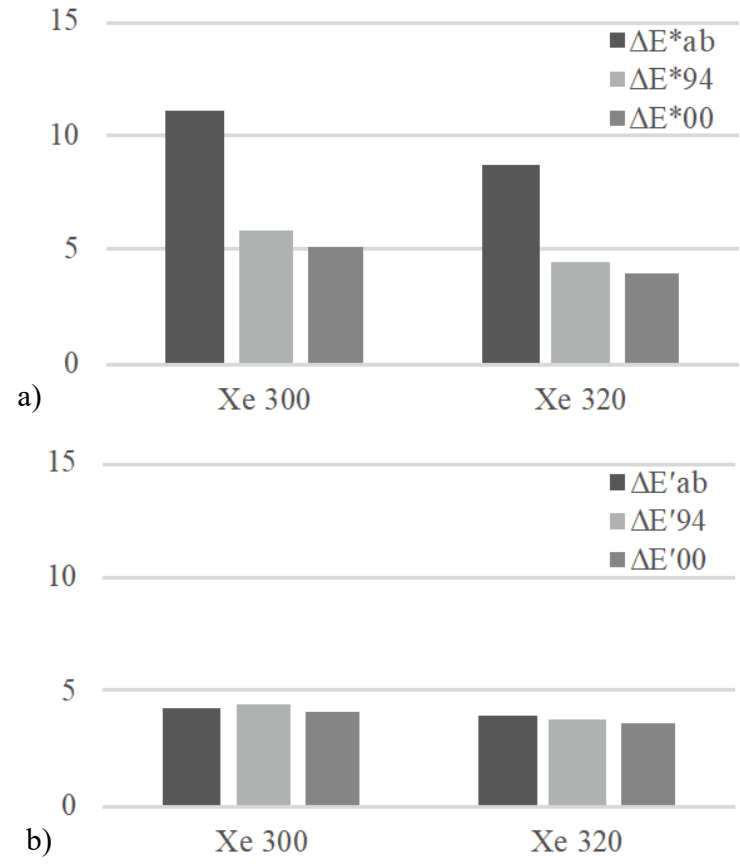

Figure 3 Average colour differences on prints after exposure to light with different spectral composition, $\lambda>300 \mathrm{~nm}$ (Xe300) or $\lambda>320 \mathrm{~nm}$ (Xe320); a) calculated according to the CIELAB, CIE94 and CIEDE2000 formulas; $b$ ) modified colour difference formulas CIELAB, CIE94 and CIEDE2000 using power functions

On the other hand, the least resistant were found to be the prints on P2 (office paper) as the calculated colour differences were the highest, regardless of the formula used (Fig. 2). Such results can be regarded as the consequence of the optical brightening agent which was added to achieve higher whiteness of the office paper and coloured prints with higher saturation.

According to our study, the application of modified colour difference formulas using their power functions leads to the results which are numerically very close and the values $\Delta E_{a b}^{\prime}, \Delta E_{94}^{\prime}$ and $\Delta E^{\prime}{ }_{00}$ for different papers are very similar (Fig. 2b). Nevertheless, the use of power functions enables the same conclusions as for the original formulas. Regarding the results, the type of selected colour difference formula does not influence the conclusions about the resistance of papers.

The resistance of prints also depends on the spectral composition of light. According to the results, larger colour differences are observed and calculated for the prints which were exposed to light which also included a certain amount of radiation with shorter wavelengths, i.e. radiation below $320 \mathrm{~nm}$ (Fig. 3). Uniform conclusions about the print resistance were obtained regardless of the type of colour difference formula applied.

Again, the use of power functions significantly compresses the calculated values (Fig. $3 b$ ) as the colour differences $\Delta E_{a b}^{\prime}, \Delta E_{94}^{\prime}$ and $\Delta E_{00}^{\prime}$ are within the range from 3.55 to 4.42 units. However, the use of power functions does not affect the conclusions regarding the influence of light since the differences are slightly lower when the radiation below $320 \mathrm{~nm}$ is excluded.

\section{CONCLUSIONS}

Three frequently used formulas for colour difference evaluation and their power function modifications were 
used to study the changes on the prints after exposure to light. The same conclusions were obtained regardless of the colour difference formula applied. The only exception was observed at the comparison of yellow and cyan prints; in this case, the CIELAB formula led to different conclusions than CIE94 and CIEDE2000 as well as their power function modifications. Generally, the CIEDE2000 formula performed the best, especially when comparing samples with a smaller colour difference. The application of power function additionally improved the agreement between the calculated and perceived colour differences.

According to the results, the black prints were the least affected by the light. On the other hand, the magenta prints exhibited the biggest colour differences. The most resistant have proven to be the prints on archival paper which included no optical brightening agents. Evidently, the presence of shortwave radiation between 320 and $300 \mathrm{~nm}$ additionally reduces the resistance of prints.

\section{REFERENCES}

[1] Ali, M., Emsley, A. M., Herman, H., \& Heywood, R.J. (2001). Spectroscopic studies of the ageing of cellulosic paper. Polymer, 42(7), 2893-290. https://doi.org/10.1016/S0032-3861(00)00691-1

[2] Fenech, A., Strlič, M., Degano, I., \& Cassar, M. (2010). Stability of chromogenic colour prints in polluted indoor environments. Polymer Degradation and Stability, 95(12), 2481-2485 https://doi.org/10.1016/j.polymdegradstab.2010.08.009

[3] Sindić, I., Bolanča Mirković, I., \& Bolanča, Z. (2015). Stability of wide format ink jet prints for outdoor application. Tehnicki vjesnik, 22(5), 1305-1312.

[4] Černič, M., Dolenc, L., \& Scheicher, L. (2006). Permanence and durability of digital prints on paper. Appl. Phys. A: Mater. Sci. Process., 83(4) 589-59. https://doi.org/10.1007/s00339-006-3543-y

[5] König, S., Muck, T., \& Gregor Svetec, D. (2012).The ageing resistance of offset and electrophotographic prints. Nord. Pulp Paper Res. J., 27(4) 739-749. https://doi.org/10.3183/NPPRJ-2012-27-04-p739-749

[6] Rat, B., Možina, K., Bračko, S., \& Podlesek, A. (2011). Influence of temperature and humidity on typographic and colorimetric properties of ink jet prints. J. Imaging Sci. Technol., 55(5), 050607/1-050607/8. https://doi.org/10.2352/J.ImagingSci.Technol.2011.55.5.050607

[7] Pastorelli, G., Cucci, C., Garcia, O., Piantanida, G., Elnaggar, A., Cassar, M., \& Strlič, M. (2014). Environmentally induced colour change during natural degradation of selected polymers. Polymer Degradation and Stability, 107, 198-209. https://doi.org/10.1016/j.polymdegradstab.2013.11.007

[8] Možina, K., Černič, M., \& Demšar, A. (2007). Nondestructive methods for chemical, optical, colorimetric and typographic characterization of a reprint. Journal of Cultural Heritage, 8(4), 339-349. https://doi.org/10.1016/j.culher.2007.03.005

[9] Blaznik, B., Možina, K., \& Bračko, S. (2013). Stability of ink-jet prints under influence of light. Nord. Pulp Paper Res. J., 28(1), 111-118. https://doi.org/10.3183/NPPRJ-2013-28-01-p111-118

[10] Huang M., Cui, G., Melgosa, M., Sánchez-Marañón, M., Li, C., Ronnier Luo, M., \& Liu, H. (2015). Power functions improving the performance of color-difference formulas. Optics Express, 23(1), 597-610. https://doi.org/10.1364/OE.23.000597
[11] Kuehni, R. G. (2008). Color difference formulas: an unsatisfactory state of affairs. Color Research and Application, 33(3), 324-326. https://doi.org/10.1002/col.20419

[12] Haberkost, M. (2013). Which color differencing equation should be used? International Circular of Graphic Education and Research, 6, 20-33.

[13] Hunt, R. W. G. (2011). Measuring Colour. $4^{\text {th }}$ Ed. Chichester, John Wiley \& Sons. https://doi.org/10.1002/9781119975595

[14] Hsien-Che, L. (2005). Introduction to colour imaging science. Cambridge, Cambridge University Press.

[15] Mc Donald, R. (Eds.). (1997). Colour Physics for Industry. $2^{\text {nd }} E d$. Bradford, Society of Dyers and Colourists.

[16] Luo, M.R., Cui, G., \& Rigg, B. The development of the CIE 2000 Color-Difference Formula: CIEDE2000. Color research and application, 26(5), 340-350.

[17] Commission Internationale de l'Éclairage (CIE): Colorimetry, Publication CIE 15:2004. (2004) Vienna: CIE Central Bureau.

[18] Mangine, H., Jakes, K., \& Noel, A. (2005). A preliminary comparison of CIE color differences to textile color acceptability using average observers. Color research and application, 30(4), 288-294. https://doi.org/10.1002/col.20124

[19] Kirchner, E., \& Dekker, N. (2011). Performance measures of colour-difference equations: correlation coefficient versus standardized residual sum of squares. J. Opt. Soc. Am. A., 28(9), 1841-1848. https://doi.org/10.1364/JOSAA.28.001841

[20] Melgosa, M., Huertas, R., \& Berns, R. S. (2008). Performance of recent advanced colour-difference formulas using the standardized residual sum of squares index. J. Opt. Soc. Am. A., 25(7), 1828-1834 https://doi.org/10.1364/JOSAA.25.001828

[21] Farnsworth-Munsell 100 HueColour Vision Test. (2017, April 10). Retrieved from http://www.colour-blindness.com/ farnsworth-munsell-100-hue-colour-visiontest/\#prettyPhoto

[22] Shamey, R., Lin, J., Sawatwarakul, W., \& Cao, R. (2014). Evaluation of Performance of Various Color-Difference Formulae Using an Experimental Black Dataset. Color Research \& Application, 39(6), 589-598. https://doi.org/10.1002/col.21844

\section{Contact information:}

Barbara BLAZNIK, mag. graf. inž., Assistant University of Ljubljana,

Faculty of Natural Sciences and Engineering,

Aškerčeva 12, 1000 Ljubljana, Slovenia

barbara.blaznik@ntf.uni-lj.si

Sabina BRAČKO, Ph.D. Associate Professor University of Ljubljana,

Faculty of Natural Sciences and Engineering,

Aškerčeva 12, 1000 Ljubljana, Slovenia

sabina.bracko@ntf.uni-lj.si 